\title{
Tryptophan requirements in small, medium, and large breed adult dogs using the indicator amino acid oxidation technique ${ }^{1}$
}

\author{
James R. Templeman, ${ }^{\dagger}$ Wilfredo D. Mansilla, ${ }^{\dagger}$ Lisa Fortener, ${ }^{\ddagger, 2}$ and Anna K. Shoveller ${ }^{\dagger, \star 3}$ \\ 'Department of Animal Biosciences, University of Guelph, Guelph, Ontario, N1G 2W1 Canada; and \\ Procter \& Gamble Co., Pet Care, Mason, OH 45040
}

\begin{abstract}
Tryptophan (Trp) is an indispensable amino acid (AA) for dogs of all life stages; however, although Trp requirements for growing dogs are derived from 3 dose-response studies, there are no empirical data on Trp requirements for adult dogs at maintenance. The study objective was to determine Trp requirements of adult dogs of 3 different breeds using the indicator amino acid oxidation (IAAO) technique. Four spayed or neutered Miniature Dachshunds $(5.28 \pm 0.29 \mathrm{~kg} \mathrm{BW}), 4$ spayed Beagles $(9.32 \pm 0.41 \mathrm{~kg} \mathrm{BW})$, and 5 neutered Labrador Retrievers $(30.51 \pm 2.09 \mathrm{~kg}$ BW) were used. After a 14-d adaptation to a Trp-adequate basal diet ( $\operatorname{Trp}=0.482 \%$ dry matter), all dogs were fed a mildly Trp-deficient diet for $2 \mathrm{~d}(\operatorname{Trp}=0.092 \%$ dry matter) before being randomly allocated to receiving 1 of 7 concentrations of Trp supplementation (final Trp content in experimental diets was $0.092,0.126,0.148,0.182,0.216,0.249$, and $0.283 \%$ dry matter) and all dogs received all Trp treatments. After 2-d adaptation to the experimental diets, dogs
\end{abstract}

underwent individual IAAO studies. Total feed was divided in 13 equal meals; at the sixth meal, dogs were fed a bolus of $\mathrm{L}-\left[1-{ }^{13} \mathrm{C}\right]-$ Phenylalanine (Phe) $(9.40 \mathrm{mg} / \mathrm{kg} \mathrm{BW})$, and thereafter, L-[1- $\left.{ }^{13} \mathrm{C}\right]-\mathrm{Phe}$ was supplied $(2.4 \mathrm{mg} / \mathrm{kg} \mathrm{BW})$ with every meal. Total production of ${ }^{13} \mathrm{CO}_{2}$ during isotopic steady state was determined by enrichment of ${ }^{13} \mathrm{CO}_{2}$ in breath samples and total production of $\mathrm{CO}_{2}$ measured using indirect calorimetry. The maintenance requirement for Trp and the 95\% confidence interval (CI) were determined using a 2-phase linear regression model. Mean Trp requirements were estimated at 0.154 , 0.218 , and $0.157 \%$ (dry-matter) for Dachshunds, Beagles, and Labradors, respectively. The upper 95\% CI were $0.187,0.269$, and $0.204 \%$ (dry-matter) for Dachshunds, Beagles, and Labradors. In conclusion, estimated Trp requirements are higher for Beagles compared with Labradors or Dachshunds, and all estimated requirements are higher than those currently recommended by the NRC and AAFCO.

Key Words: adult dogs, indirect amino acid oxidation, maintenance, tryptophan

(C) The Author $(s)$ 2019. Published by Oxford University Press on behalf of the American Society of Animal Science. All rights reserved. For permissions, please e-mail: journals.permissions@oup.com.

J. Anim. Sci. 2019.97:3274-3285 doi: $10.1093 /$ jas/skz142

\section{INTRODUCTION}

Tryptophan (Trp) is an indispensable amino acid (AA) for domestic canines (Canis lupus familiaris) that is imperative for a number of

\footnotetext{
${ }^{1}$ Funding for this work was provided by Procter \& Gamble, Mason, OH 45040.

${ }^{2}$ Current address: Mars Pet Care, Lewisburg, Ohio, 45338

${ }^{3}$ Corresponding author: ashovell@uoguelph.ca

Received March 18, 2019.

Accepted April 22, 2019.
}

metabolic processes. Aside from its primary role in protein synthesis, Trp acts as a precursor of the kynurenine and serotonergic pathways, contributing to the synthesis of kyurenic acid, quinolinic acid, NAD/NADP, niacin, serotonin, and melatonin (Triebwasser et al., 1976; Richard et al., 2009; Fernstrom, 2013). However, despite the fact that dogs cannot endogenously synthesize Trp and as such rely exclusively on dietary Trp to meet requirements, there is a dearth of data to support recommended minimal concentrations of Trp in the diet for adult dogs at maintenance. 
Although Trp requirements for immature dogs are based on data derived from dose-response studies (Milner, 1979; Burns and Milner, 1982; Czarnecki and Baker, 1982; NRC, 2006), current recommended maintenance Trp requirements for adult dogs are based off the lowest concentrations reported in one doctoral dissertation and one peerreviewed report wherein dogs were fed low-protein diets for an extended period of time and displayed no clinical signs of deficiency (Ward, 1976; Sanderson et al., 2001; NRC, 2006). The study by Sanderson et al. (2001) as well as those studies used to determine Trp requirements of growing dogs, all utilized Beagles. Thus, this one breed serves as a basis for suggested requirements of Trp for dogs of all breeds and breed sizes. There is extensive variability among breed types in body weight, conformation, lean mass and adiposity, as well as a number of other physical characteristics. These differences potentially cause variation in the ways in which a particular breed will utilize dietary AA, as well as the concentration of each indispensable AA that the animal needs to maintain an ideal BW and sustain optimal metabolic processes. Gaining a better understanding of indispensable amino acid requirements based on breed size is a crucial next step in canine nutrition research and is critical as we consider novel protein ingredients.

Amino acid requirements have traditionally been determined using nitrogen balance and growth performance techniques; however, concerns have been raised that this method may underestimate AA recommendations by upwards of $40 \%$ when compared with AA oxidation techniques (Zello et al., 1995; Elango et al., 2012). The indicator amino acid oxidation (IAAO) technique represents a more rapid, less invasive, and more sensitive method of determining whole body AA requirements (Pencharz and Ball, 2003; Shoveller at al., 2017). The IAAO technique has been used to determine estimated AA requirements for a number of mammalian subjects (Ball and Bayley, 1984; Zello et al., 1995; Lazaris-Bruuner et al., 1998; Tabiri et al., 2002) and has recently been validated in dogs (Shoveller et al., 2017). This study is one of a series working to determine AA requirements of adult dogs of different breeds. We have previously determined the requirements for phenylalanine (Phe) in adult dogs of different breeds using the direct oxidation technique (Mansilla et al., 2018a).

The objective of the present study was to measure the dietary Trp requirement of small (Miniature Dachshunds), medium (Beagles), and large breed dogs (Labrador Retrievers) using the
IAAO technique. We hypothesized that the mean Trp requirement of adult dogs would differ among the 3 breeds and that the requirements for all breeds would be greater than the current NRC (2006) recommendation.

\section{MATERIALS AND METHODS}

\section{Animals and Housing}

The present experiment was approved by the Procter and Gamble Pet Care's Institutional Animal Care and Use Committee (IACUC). A total of 13 dogs were used (Table 1), 4 adult spayed and neutered Miniature Dachshunds $(5.28 \pm 0.29 \mathrm{~kg} \mathrm{BW}$; $1.23 \pm 0.03 \mathrm{yr}$ old, mean $\pm \mathrm{SD}), 4$ adult spayed Beagles $(9.32 \pm 0.41 \mathrm{~kg} \mathrm{BW} ; 5.39 \pm 0.29 \mathrm{yr}$ old, mean $\pm \mathrm{SD})$, and 5 neutered Labradors $(30.51 \pm 2.09 \mathrm{~kg}$ $\mathrm{BW} ; 3.67 \pm 1.54 \mathrm{yr}$ old, mean \pm SD). Numerous studies that have estimated indispensable AA requirements for human, swine, poultry, and canine subjects using the IAAO method have done so using similar numbers of subjects $(n=4-6$; LazarisBrunner et al., 1998; Bross et al., 2000; Wilson et al., 2000; Di Buono et al., 2001; Roberts et al., 2001; Courtney-Martin et al., 2002; Kriengsinyos et al., 2002; Tabiri et al., 2002; Coleman et al., 2003; Mager et al., 2003; Hsu et al., 2006; Turner et al., 2006; Elango et al., 2007; Moehn et al., 2008; Tang et al., 2014; Mansilla et al., 2018a). All dogs resided at Procter and Gamble Pet Care (Lewisburg, $\mathrm{OH}$ ) and were considered healthy based on a general health evaluation by a licensed veterinarian prior to the study. During the study, dogs were pair-housed in kennels $(2.4 \times 2.4 \mathrm{~m})$ in a temperature controlled building $\left(22^{\circ} \mathrm{C}\right)$ and with a lighting schedule of 12 h:12 h light:dark. Dogs received daily socialization,

Table 1. Gender, age, and BW of dogs used at the commencement of the study period

\begin{tabular}{llcc}
\hline \hline Breed & Gender & Age, yr & BW, kg \\
\hline Dachshund & Female & 1.24 & 5.20 \\
Dachshund & Female & 1.18 & 5.10 \\
Dachshund & Female & 1.26 & 5.10 \\
Dachshund & Female & 1.24 & 5.70 \\
Beagle & Female & 5.37 & 9.00 \\
Beagle & Female & 5.38 & 9.25 \\
Beagle & Female & 5.76 & 9.92 \\
Beagle & Female & 5.06 & 9.12 \\
Labrador & Male & 2.54 & 32.80 \\
Labrador & Male & 5.36 & 32.30 \\
Labrador & Male & 2.54 & 30.60 \\
Labrador & Male & 5.36 & 28.00 \\
Labrador & Male & 2.54 & 28.85 \\
\hline
\end{tabular}


exercise, and regular veterinary care as reported previously (Shoveller et al., 2017).

\section{Diets and Study Design}

A basal diet was formulated to meet or exceed requirements for all indispensable AA according to NRC (2006; Table 2). The extruded kibble basal diet was fed twice daily (0700 and $1300 \mathrm{~h}$ ) during 14 $\mathrm{d}$ prior to the beginning of the experiment (adaptation period) in amounts known to maintain dog individual BW. After the 14-d adaptation period to the basal diet, a test diet (similar to basal diet but without added crystalline Trp; final Trp $=0.092 \%$ on a dry-matter basis; Table 2) was fed to the dogs at $15 \mathrm{~g} / \mathrm{kg}$ of BW for Beagles and at $20 \mathrm{~g} / \mathrm{kg}$ of BW for Miniature Dachshunds and Labradors for $2 \mathrm{~d}$ prior to each IAAO study. Because AA requirements are a function of BW and lean tissue, providing dogs with equal food intake across all the Trp treatments within each breed was a critical design component. This design consideration ensured that dogs received equal amounts of dietary nitrogen, equal and excess tyrosine (Tyr) to shunt Phe to either protein synthesis or oxidation and not to synthesize Tyr (Rafii et al., 2008), and equal Phe intake to ensure equal Phe pool contributions. The test diets were supplemented with 1 of 7 Trp (Skidmore Sales \& Distributing, West Chester Township, $\mathrm{OH}$ ) solutions $(0,1.0,1.67,2.67,3.67,4.67$, and $5.67 \mathrm{~g} / \mathrm{L})$ at $6.0 \mathrm{~mL} / \mathrm{kg} \mathrm{BW}$ for Beagle dogs and at $4.5 \mathrm{~mL} /$ $\mathrm{kg}$ BW for Miniature Dachshunds and Labradors. To maintain similar nitrogen content among all solutions, Alanine (Ala) was added (4.95, 4.08, 3.20, 2.33, 1.46, 0.87, and $0 \mathrm{~g} / \mathrm{L}$ for solutions 1 to 7 , respectively). The final Trp contents in the test diet plus the supplemental solutions were $0.092,0.126$, $0.148,0.182,0.216,0.249$, and $0.283 \%$ on a drymatter basis (experimental diets). After the 2-d adaptation period to the experimental diet (Moehn et al., 2004), the IAAO study combined with indirect calorimetry was conducted. After each IAAO study, dogs returned to the basal diet for $4 \mathrm{~d}$ before being fed another test diet with a different solution and conducting the next IAAO study. This 7-d feeding regimen was repeated 7 times. Dogs were assigned to the experimental treatments randomly, and no dog received the same order of treatments. At completion of the study, all dogs had recieved each of the 7 experimental diets. Blood samples $(3 \mathrm{~mL})$ were collected from the jugular vein in serum vacutainers (Becton \& Dickinson, Franklin Lakes, $\mathrm{NJ}$ ) at the end of each IAAO study and represented fed state serum AA concentrations. Throughout
Table 2. Ingredient composition and analyzed nutrient contents of the basal diet (dry-matter basis)

\begin{tabular}{|c|c|}
\hline Ingredient & $\mathrm{g} / \mathrm{kg}$ \\
\hline$\overline{\text { Corn starch }}$ & 539.9 \\
\hline Chicken fat & 146.7 \\
\hline Chicken meal & 71.9 \\
\hline Yellow corn & 56.8 \\
\hline Brewer's rice & 56.8 \\
\hline Amino acid premix ${ }^{1}$ & 85.3 \\
\hline Beet pulp & 34.2 \\
\hline Dicalcium phosphate & 32.6 \\
\hline Chicken flavor & 22.7 \\
\hline Potassium chloride & 14.9 \\
\hline Sodium bicarbonate & 11.3 \\
\hline Chicken liver flavor & 5.7 \\
\hline Brewer's yeast & 5.7 \\
\hline Ground flax & 5.7 \\
\hline Choline chloride & 5.0 \\
\hline Vitamin premix ${ }^{2}$ & 4.8 \\
\hline Sodium hexametaphosphate & 4.6 \\
\hline Calcium carbonate & 6.5 \\
\hline Mineral premix ${ }^{3}$ & 3.9 \\
\hline Fish oil & 3.3 \\
\hline Sodium chloride & 2.0 \\
\hline Monosodium phosphate & 2.6 \\
\hline Ethoxyquin & 0.57 \\
\hline Nutrient contents & $\begin{array}{l}\text { Analyzed } \\
\text { content }\end{array}$ \\
\hline Metabolizable energy, $\mathrm{kcal} / \mathrm{kg}$ (calculated) ${ }^{4} \mathrm{Mcal} / \mathrm{kg}$ & 3,700 \\
\hline $\mathrm{DM}, \% 5$ & 89.01 \\
\hline $\mathrm{CP}, \%$ & 12.63 \\
\hline Arg, $\%$ & 1.122 \\
\hline Cys, $\%$ & 0.781 \\
\hline His, $\%$ & 0.449 \\
\hline Ile, $\%$ & 0.618 \\
\hline Leu, $\%$ & 1.040 \\
\hline Lys, $\%$ & 0.726 \\
\hline Met, $\%$ & 0.570 \\
\hline Phe, \% & 0.724 \\
\hline Thr, $\%$ & 0.827 \\
\hline $\operatorname{Trp}, \%$ & $(0.092)^{6}$ \\
\hline Tyr, \% & 0.611 \\
\hline Val, \% & 0.648 \\
\hline
\end{tabular}

${ }^{1}$ Provides per kg of final diet: $5.1 \mathrm{~g}$ of Arg, Cys, His, Ile, Leu, Lys, Met, Phe, Thr, Trp, Tyr, and Val each. Trp was removed for the test diet.

${ }^{2}$ Vitamin premix contained per kg: 6,650 K IU Vitamin A, 365,000 IU Vitamin D3, 100,400 IU Vitamin E, 4,100 mg Thiamine, 2,500 mg Niacin, 2,000 mg Pyridoxine, 7,750 mg d-Pantothenic acid, $115 \mathrm{mg}$ Folic acid, $45 \mathrm{mg}$ Vitamin B12, 2,500 mg Inositol, 13,750 mg Vitamin $\mathrm{C}, 1,200 \mathrm{mg} \beta$-carotene.

${ }^{3}$ Mineral premix contained per $\mathrm{kg}: 150 \mathrm{mg}$ Cobalt Carbonate, 4,500 mg Copper Sulfate, $900 \mathrm{mg}$ Potassium Iodine, 72,000 mg Iron Sulfate, 8,000 mg Manganese Oxide, 5,800 mg Manganese Sulfate, $60,000 \mathrm{mg}$ Sodium Selenite.

${ }^{4}$ Calculated metabolizable energy based on modified Atwater Values and presented on an as-fed basis.

${ }^{5}$ Dry matter presented on an as-fed basis.

${ }^{6}$ Value presented in parentheses corresponds to the Trp-deficient test diet; AA premix without crystalline Trp. 
the whole study, dogs had access to fresh water via an automatic watering system. All dogs consumed their entire daily diet offerings (basal or test diets).

\section{Indicator Amino Acid Oxidation Studies}

The day when the IAAO study was conducted, dogs were moved to individual respiration calorimetry chambers to which they had previously been habituated. After $30 \mathrm{~min}$ of gas equilibration, 3 fasting respiration/indirect calorimetry measurements were taken over 3 consecutive 25 -min periods to determine resting volume of $\mathrm{CO}_{2}$ and $\mathrm{O}_{2}$ produced $\left(\mathrm{VCO}_{2} ; \mathrm{VO}_{2}\right)$ by each dog. Dogs were then fed (Time 0) their corresponding feed allowance divided in 13 equal meals; the first 3 meals were fed every $10 \mathrm{~min}$ to induce a fed state, and the other 10 meals were fed every $25 \mathrm{~min}$. The total amount of feed fed during the IAAO study was based on BW measured the same day in the morning after $18 \mathrm{~h}$ of fasting $(20 \mathrm{~g} / \mathrm{kg}$ of BW for Beagles and $15 \mathrm{~g} /$ $\mathrm{kg} \mathrm{BW}$ for Miniature Dachshunds and Labradors). Background ${ }^{13} \mathrm{C}$ enrichment was determined by the collection of $\mathrm{CO}_{2}$ samples over 3 consecutive 25-min periods. The sixth meal $(95 \mathrm{~min}$ after first feeding) contained a priming dose $(9.40 \mathrm{mg} / \mathrm{kg}$ BW) of L-[1-13 C]-Phe (99\%; Cambridge Isotope Laboratories, Inc., Tewksbury, MA). To maintain the supply of L-[1-13 C]-Phe, the following 7 meals contained constant doses $(2.40 \mathrm{mg} / \mathrm{kg} \mathrm{BW})$ of L-[1$\left.{ }^{13} \mathrm{C}\right]$-Phe for all dogs. Expired $\mathrm{CO}_{2}$ was collected over the last eight 25-min periods. Overall during each IAAO study, each dog spent $\sim 6.3 \mathrm{~h}$ inside the calorimetry chamber. Additional details regarding the timeline for each IAAO study can be found in Mansilla et al. (2018a).

\section{Sample Collection and Analysis}

Nitrogen content in the basal diet was analyzed with a LECO analyzer (LECO Corporation, St. Joseph, MI). Amino acid content in the test diet was analyzed using AOAC method 999.12 (AOAC International, 2000). Calorimetry data were collected automatically using Qubit calorimetry software (Customized Gas Exchange System and Software for Animal Respirometry; Qubit Systems Inc., Kingston, ON). Measured $\mathrm{VCO}_{2}$ during fasting and fed states were averaged over the collection periods to obtain a mean fasting and fed $\mathrm{VCO}_{2}$ for each dog. Background and enriched samples of $\mathrm{CO}_{2}$ were collected by trapping subsamples of expired $\mathrm{CO}_{2}$ in $1 \mathrm{M} \mathrm{NaOH}$. The $\mathrm{NaOH}$ solution was subsampled and samples were stored at room temperature until further analysis. The enrichment of ${ }^{13} \mathrm{C}$ in breath $\mathrm{CO}_{2}$ captured in $\mathrm{NaOH}$ solution was measured by continuous-flow isotope ratio mass spectrometry (20/20 isotope analyzer; PDZ Europa Ltd., Cheshire, United Kingdom). Enrichment of $\mathrm{CO}_{2}$ samples was expressed above background samples (Atom percent excess; APE).

\section{Calculations}

The fraction of ${ }^{13} \mathrm{CO}_{2}$ released per $\mathrm{kg}$ of $\mathrm{BW}$ per $\mathrm{h}\left(\mathrm{F}^{13} \mathrm{CO}_{2}, \mathrm{mmol} \cdot \mathrm{kg}^{-1} \cdot \mathrm{h}^{-1}\right)$ was calculated using the following equation: $F^{13} \mathrm{CO}_{2}=\left(\mathrm{FCO}_{2}\right)\left(\mathrm{ECO}_{2}\right)(44.6)$ $(60) /[(\mathrm{BW})(1.0)(100)]$, in which $\mathrm{FCO}_{2}$ is the average production of $\mathrm{CO}_{2}$ during the isotope steady state phase $(\mathrm{mL} / \mathrm{min}) ; \mathrm{ECO}_{2}$ is the average ${ }^{13} \mathrm{CO}_{2}$ enrichment in expired breath at isotopic steady state (APE, \%); and BW is the weight of the dog $(\mathrm{kg})$. The constants $44.6(\mathrm{mmol} / \mathrm{mL})$ and $60(\mathrm{~min} / \mathrm{h})$ convert the $\mathrm{FCO}_{2}$ to micromoles per hour; the factor 100 changes APE to a fraction; and the 1.0 is the retention factor of $\mathrm{CO}_{2}$ in the body due to bicarbonate fixation as reported previously (Shoveller et al., 2017). Resting and fed energy expenditure (REE, FEE) were calculated based on $\mathrm{VO}_{2}$ and $\mathrm{VCO}_{2}$ using the modified Weir equation (Weir, 1949). Energy expenditure (kcal/d) was expressed in relation to metabolic $\mathrm{BW}\left(\mathrm{BW}^{0.75}\right)$ for all dog breed sizes.

\section{Body Composition Determination}

Lean body mass (LBM) was determined during the 7-wk study using an X-Ray Bone Densitometer (Model Delphi A, Hologic Inc., Malborough, MA) on Beagles and Labrador Retrievers. Lean body mass could not be determined in Miniature Dachshunds due to their unique body characteristics. Dogs were fasted overnight (18 h since last meal) and sedated using Dexmedetomidine (Dexdomitor, Pfizer, NY) at a dose of $0.02 \mathrm{mg} / \mathrm{kg}$ and Carprofen (Rimadyl, Pfizer, NY) at a dose of 2 to $4 \mathrm{mg} / \mathrm{kg}$ administered i.m. Propofol (Propoflo, Abbott, Chicago, IL) at a dose of 5 to $7 \mathrm{mg} / \mathrm{kg}$ was administered i.v. for induction. Dogs were positioned on their sternum with the cranial aspect of ante brachium placed on the table to ensure the phalanges faced caudally. The hind limbs were extended with the tail placed straight and in between the hind limbs. A wholebody scan was performed of the following regions: left arm, right arm, trunk, left leg, right leg, and head. Scans were done in triplicate for each dog and the median value of the 3 scans was recorded. Body mass composition (i.e., mineral, fat, lean, and water 
contents) was determined in the left and right arms and legs, trunk, and head (data not shown). Whole body composition was determined by the sum of all regions measured on individual dogs. Following the scan, atipamezole (Antisedan, Pfizer, NY) was administered to each dog at a dose of $0.2 \mathrm{mg} / \mathrm{kg}$. Dogs were placed in a heated cage until fully recovered and monitored for $1 \mathrm{wk}$ for complications.

\section{Statistical Analysis}

The effect of Trp content in the test diet on $\mathrm{F}^{13} \mathrm{CO}_{2}$ was analyzed using PROC MIXED of SAS (v. 9.4; SAS Institute Inc., Cary, NC) with diet as a fixed effect and dog as a random effect. The estimate of the mean Trp requirement and the upper 95\% confidence intervals (CI) for individual dog breeds were derived by breakpoint analysis of the $\mathrm{F}^{13} \mathrm{CO}_{2} / \mathrm{kg} \mathrm{BW}$ using a 2-phase linear regression model as reported previously (Shoveller et al., 2017). Differences in AA concentration in blood were determined comparing each dietary Trp contents against the lowest Trp diet $(0.082 \%)$ using the Dunnett test. Mean Trp requirements were also calculated with Trp concentration in serum data using the 2-phase linear regression model. Within different breed sizes, BW and the calorimetry data were analyzed using PROC MIXED of SAS (v. 9.4; SAS Institute Inc., Cary, NC) with diet as a fixed effect and dog as a random effect. Because we had previously only used the direct oxidation approach and no data to do a power calculation prior to the conduct of the current study, a post hoc power calculation was done for the 2-phase linear regression model used for each breed size using a data step of SAS (v. 9.4; SAS Institute Inc., Cary, NC). Results were considered statistically significant at $P \leq 0.05$, and a trend when $P \leq 0.10$.

\section{RESULTS}

During the study period, all dogs maintained their body condition score and BW. Throughout every IAAO study, all dogs consumed all their meals immediately after each feeding. For each different test diet, isotopic steady state was reached for all dogs (data not shown). Using the 2-phase linear regression relating $\mathrm{F}^{13} \mathrm{CO}_{2}$ to the concentrations of supplemental dietary Trp, the mean Trp requirement for Miniature Dachshunds was estimated to be $0.154 \%$ with an upper $95 \%$ CI of $0.187 \%$ on a dry-matter basis (DMB) (Figure 1A). For Beagles, the mean Trp requirement was estimated to be $0.218 \%$ and the upper $95 \%$ CI was estimated to be
$0.269 \%$ on a DMB (Figure 1B). The mean Trp requirement for Labrador Retrievers was estimated at $0.157 \%$ with an upper $95 \%$ CI of $0.204 \%$ on a DMB (Figure 1C). The 2-phase linear regression was also fitted relative to Trp intake $(\mathrm{mg} / \mathrm{kg} \mathrm{BW})$ to account for differences in feed intake $(15,20$, and $15 \mathrm{~g} / \mathrm{kg}$ BW for Miniature Dachshunds, Beagles, and Labradors Retrievers, respectively). The breakpoint for Miniature Dachshunds (mean Trp requirement) was estimated at $20.58 \mathrm{mg} / \mathrm{kg} \mathrm{BW}$ with an upper $95 \% \mathrm{CI}$ of $25.00 \mathrm{mg} / \mathrm{kg} \mathrm{BW}$. For Beagles and Labrador Retrievers, the breakpoint was at 38.78 and $20.94 \mathrm{mg} / \mathrm{kg}$ BW of Trp with a $95 \%$ CI of 47.92 and $27.21 \mathrm{mg} / \mathrm{kg} \mathrm{BW}$, respectively. When pooling the data from all breeds, the model was not significant $(P>0.10)$, likely due to breed differences in estimated requirements. A power of greater than 0.8 was achieved for all 3 breed sizes with a post hoc power analysis for each 2-phase linear regression model, suggesting that each individual breakpoint estimate for Trp was sufficiently powered.

No concentration of Trp in any of the test diets affected energy expenditure (resting, REE; or fasted, FEE) or respiratory quotient (RQ; fasted or fed; $P>0.10$ ). For comparison among breeds, BW, LBM, and the indirect calorimetry data were pooled (Table 3). Mean REE and FEE for the Dachshunds were 56.1 and $95.4 \mathrm{kcal}$ per $\mathrm{kg} \mathrm{BW}{ }^{0.75}$, respectively; for the Beagles were 74.5 and $88.8 \mathrm{kcal}$ per $\mathrm{kg} \mathrm{BW}^{0.75}$, respectively; and for the Labradors were 72.9 and $89.9 \mathrm{kcal}$ per $\mathrm{kg} \mathrm{BW}^{0.75}$, respectively. Mean fasted and fed RQ for the Dachshunds were 0.794 and 0.843 , respectively; for the Beagles were 0.789 and 0.871, respectively; and for the Labradors were 0.769 and 0.841 , respectively. Predictably, BW differed among the 3 breeds with the Labradors having the greatest mean BW and the Dachshunds having the lowest $(P \leq 0.05)$. The absolute LBM $(\mathrm{kg})$ was lower for the Beagles compared with the Labradors $(P \leq 0.05)$ as expected. However, LBM relative to BW $(\%)$ was similar for both breeds and represented $\sim 81 \%$ of $\mathrm{BW}(P>0.10)$ and representative of a healthy lean dog. Miniature Dachshunds had a lower resting EE per kg metabolic BW $\left(\mathrm{BW}^{0.75}\right)$ compared with the Beagles and Labradors $(P \leq 0.05)$, but there was no difference among breeds in the fed EE per $\mathrm{kg} \mathrm{BW}^{0.75}(P>0.10)$. Fasting RQ did not differ among breeds $(P>0.10)$, but the Beagles had a greater fed RQ when compared with Miniature Dachshunds and Labrador Retrievers $(P \leq 0.05)$. The rate of $\mathrm{CO}_{2}$ production and $\mathrm{O}_{2}$ consumption was different among all breeds with the Labradors highest rates and the Miniature Dachshunds having the lowest rates $(P \leq 0.05)$. 

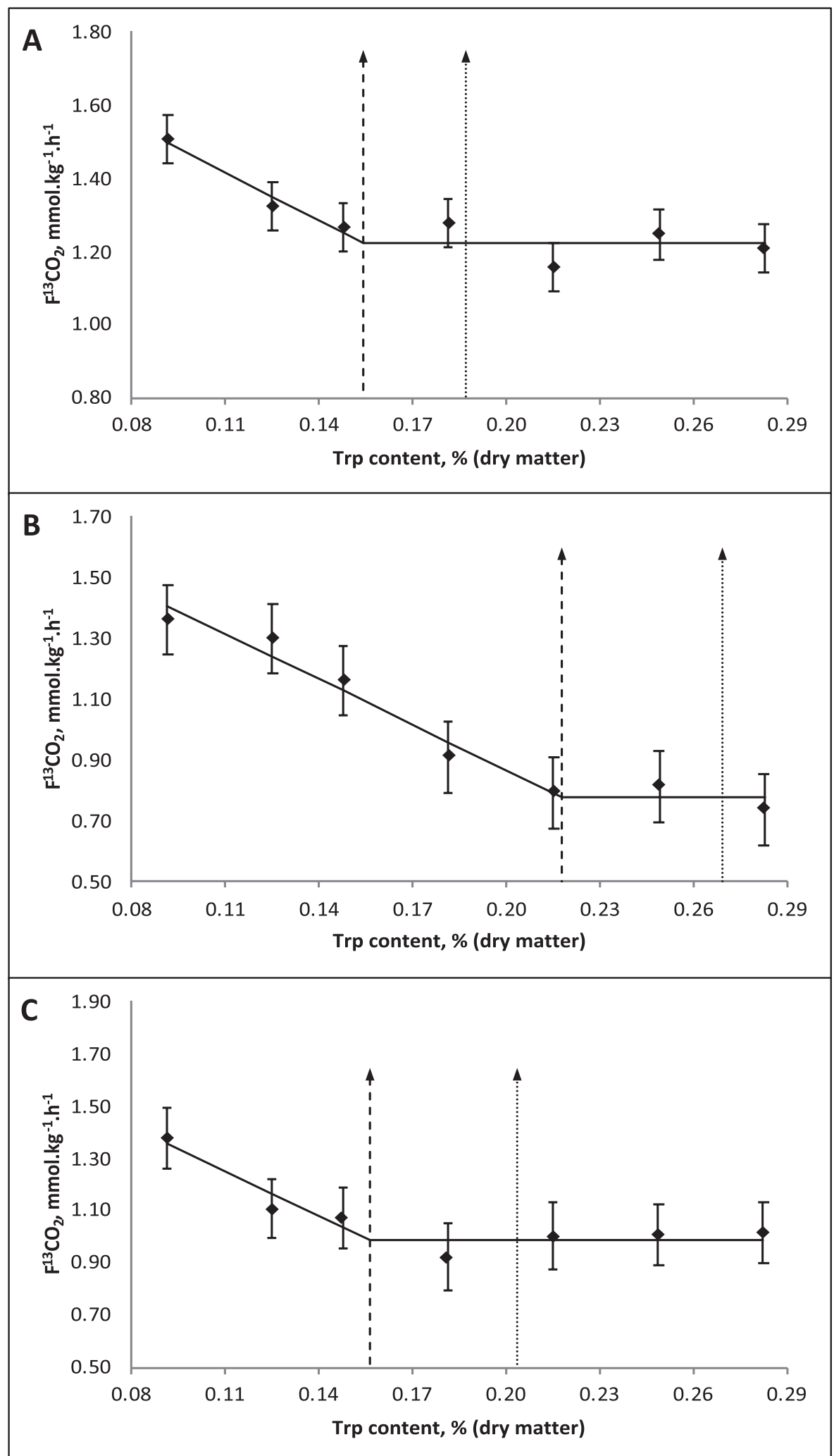

Figure 1. Production of ${ }^{13} \mathrm{CO}_{2}$ from the oxidation of orally administered $\mathrm{L}-\left[1-{ }^{13} \mathrm{C}\right]$-Phe in adult dogs of different breeds fed experimental diets with increasing concentrations of Trp. Miniature Dachshunds (A), Beagles (B), Labrador Retrievers (C). Dashed lines: estimated Trp requirement $(0.154 \%$ for A, $0.218 \%$ for B, $0.157 \%$ for C); dotted lines represent $95 \%$ CI for Trp requirement $(0.187 \%$ for A, $0.269 \%$ for B, $0.204 \%$ for C). Data points represent mean $+\mathrm{SE}$ of samples $(n=4$ for $\mathrm{A}$ and $\mathrm{B}, n=5$ for $\mathrm{C})$.

No breakpoint could be detected for any breed when using Trp concentration in plasma $(P>0.10)$; however, plasma Trp increased linearly with dietary
Trp concentrations for all 3 breeds (Linear regression in the 2 phase-model; Table 4). For Miniature Dachshunds, Trp concentrations in serum plasma 
Table 3. Body weight, lean body mass, and indirect calorimetry data $\left( \pm \mathrm{SE}^{1}\right)$ of the dogs used

\begin{tabular}{|c|c|c|c|c|}
\hline & Miniature Dachshunds & Beagles & Labrador Retrievers & Pooled ANOVA \\
\hline & $n=4$ & $n=4$ & $n=5$ & $P$ \\
\hline$\overline{\mathrm{BW}^{2}, \mathrm{~kg}}$ & $5.23 \pm 0.20^{\mathrm{c}}$ & $9.22 \pm 0.48^{b}$ & $30.83 \pm 0.72^{\mathrm{a}}$ & $<0.001$ \\
\hline $\mathrm{LBM}^{3}, \mathrm{~kg}$ & - & $7.59 \pm 0.74^{b}$ & $24.83 \pm 1.14^{\mathrm{a}}$ & $<0.001$ \\
\hline $\mathrm{LBM}, \% \mathrm{BW}$ & - & $82.46 \pm 2.96$ & $80.35 \pm 4.54$ & 0.699 \\
\hline REE, Kcal/BW ${ }^{0.75}$ & $56.06 \pm 2.13^{\mathrm{b}}$ & $74.45 \pm 4.38^{\mathrm{a}}$ & $72.91 \pm 6.45^{\mathrm{a}}$ & $<0.001$ \\
\hline FEE, Kcal/BW 0.75 & $95.35 \pm 5.55$ & $88.77 \pm 18.0$ & $89.9 \pm 27.7$ & 0.927 \\
\hline Fasting RQ & $0.794 \pm 0.008$ & $0.789 \pm 0.012$ & $0.769 \pm 0.016$ & 0.365 \\
\hline Fed RQ & $0.843 \pm 0.004^{b}$ & $0.871 \pm 0.007^{\mathrm{a}}$ & $0.841 \pm 0.009^{b}$ & 0.002 \\
\hline Fed $\mathrm{VO}_{2}, \mathrm{~L} / \mathrm{min}$ & $2.51 \pm 0.24^{\mathrm{c}}$ & $3.96 \pm 0.45^{\mathrm{b}}$ & $9.95 \pm 0.66^{\mathrm{a}}$ & $<0.001$ \\
\hline Fed $\mathrm{VCO}_{2}, \mathrm{~L} / \mathrm{min}$ & $2.09 \pm 0.21^{\mathrm{c}}$ & $3.46 \pm 0.37^{\mathrm{b}}$ & $8.38 \pm 0.53^{\mathrm{a}}$ & $<0.001$ \\
\hline
\end{tabular}

${ }^{1}$ Standard error of the mean, $n=4$ for Miniature Dachshunds and Beagles, $n=5$ for Labrador Retrievers.

${ }^{2}$ Body weight averages throughout the entire trial period.

${ }^{3} \mathrm{LBM}=$ lean body mass; REE = resting energy expenditure; $\mathrm{FEE}=$ fed energy expenditure; $\mathrm{RQ}=$ respiratory quotient; $\mathrm{VCO}_{2}=$ carbon dioxide production; $\mathrm{VO}_{2}=$ oxygen consumption .

a,b,c Values in a row with a different superscript are different at $P \leq 0.05$.

were greater for dogs fed $0.182,0.249$, and $0.283 \%$ dietary Trp compared with the lowest Trp concentration $(P \leq 0.05)$. For Labrador Retrievers, Trp concentrations in serum were greater at the highest 4 dietary Trp concentrations compared with $0.092 \% \operatorname{Trp}(P \leq 0.05)$. For Beagles, there was no difference in the serum Trp at any of the dietary Trp concentrations when compared with $0.092 \%$ Trp $(P>0.10)$. Plasma Ala concentrations did not increase with higher Ala supplementation for any breeds at any concentration of dietary supplementation $(P>0.10)$. Large-neutral-amino-acid concentrations (LNAA: Phe, Tyr, Valine, Isoleucine, Leucine, and Lysine) did not differ from any diet concentration for any breed $(P>0.10)$. Labradors and Dachsunds fed diets with the 4 highest concentrations of $\operatorname{Trp}(0.182-0.283 \%)$ had significantly higher Trp: LNAA ratios in serum compared with dogs fed diets with the lowest concentration of Trp $(0.092 \% ; P \leq 0.05)$. Plasma Phe and Tyr were not different among dietary treatments within any breed, suggesting no differences in the Phe pool size and supports the use of Phe oxidation as an indirect measure of protein synthesis.

\section{DISCUSSION}

To the best of our knowledge, this is the first dose-response study evaluating the Trp requirements of adult dogs at maintenance. Currently, NRC (2006) recommends maintenance requirements of Trp for adult dogs based on the lowest concentration reported in 2 studies in which dogs were fed at maintenance low-protein diets, yet no observable clinical signs of AA deficiency were reported (Ward, 1976; Sanderson et al., 2001). Based on these studies, NRC (2006) suggests a minimal requirement (MR) of Trp for adult dogs of $0.11 \%$ on a DMB and a recommended allowance (RA) of $0.14 \%$ DMB. When the upper $95 \%$ CI was determined for each breed in the current study, on a DMB these estimates exceeded the NRC (2006) RA by $\sim 35 \%$ and the recommendations put forth by AAFCO (2014) by $\sim 25 \%$ (Table 5). When Trp requirements are expressed as $\mathrm{mg} / \mathrm{kg} \mathrm{BW}$, the RA estimated for Beagles and Labradors greatly exceeded the RA for adult dogs proposed by the NRC, but the estimate for Dachshunds was lower than that suggested allowance (Table 5). These data highlight the importance of determining discrete AA for different breeds that may vary in BW, conformation, and underlying metabolic processes. Moreover, it must be considered that the supply of available Trp changes depending on the nutrient bioavailability of the ingredients used for diet formulation. Crystalline Trp is estimated to be $100 \%$ bioavailable; and in this study, crystalline Trp made up half of the total dietary Trp. Thus, in commercial adult dog diets using intact protein-containing ingredients (assumed AA bioavailability of $80 \%$; NRC, 2006), the estimates derived from the semipurified diets used in the current study would underestimate Trp needs in adult dogs fed commercial maintenance diets. However, it must be acknowledged that when formulating dog diets with typical ingredients, increasing concentration of Trp with intact ingredients to meet the requirements suggested in this report may be challenging as Trp is found in relatively low concentrations in protein-based ingredients in relation to other indispensable AA. As such, when formulating commercial diets for adult dogs, crystalline Trp supplementation may be necessary similar 
Table 4. Serum concentration of selected AA in adult Miniature Dachshunds, Beagles, and Labrador Retrievers fed diets containing increasing concentrations of Trp

\begin{tabular}{|c|c|c|c|c|c|c|c|c|}
\hline \multicolumn{9}{|c|}{ Miniature Dachshunds } \\
\hline & \multicolumn{7}{|c|}{ Dietary Trp, $\%$} & \multirow[b]{3}{*}{ SEM $^{1}$} \\
\hline & 0.092 & 0.126 & 0.148 & 0.182 & 0.216 & 0.249 & 0.283 & \\
\hline & $n=4$ & $n=4$ & $n=4$ & $n=4$ & $n=4$ & $n=4$ & $n=4$ & \\
\hline$\overline{\operatorname{Trp}, \mu \mathrm{M}}$ & 76.7 & 72.7 & 131.1 & $158.4^{*}$ & 126.5 & $156.1^{*}$ & $147.3^{*}$ & 16.8 \\
\hline Ala, $\mu \mathrm{M}$ & 422.3 & 506.5 & 634.4 & 328.4 & 462.1 & 494.9 & 458.8 & 96.2 \\
\hline Val, $\mu \mathrm{M}$ & 306.2 & 273.6 & 331.2 & 311.9 & 275.8 & 277.4 & 283.2 & 32.2 \\
\hline Phe, $\mu \mathrm{M}$ & 67.1 & 78.2 & 151.6 & 80.4 & 112.3 & 96.0 & 71.8 & 31.2 \\
\hline Ile, $\mu \mathrm{M}$ & 106.6 & 100.8 & 139.7 & 108.6 & 108.2 & 112.3 & 110.5 & 15.8 \\
\hline Leu, $\mu \mathrm{M}$ & 151.6 & 138.7 & 185.9 & 148.0 & 148.8 & 135.0 & 139.2 & 22.7 \\
\hline Lys, $\mu \mathrm{M}$ & 239.7 & 236.2 & 248.1 & 217.0 & 192.6 & 242.7 & 215.9 & 20.7 \\
\hline Tyr, $\mu \mathrm{M}$ & 62.4 & 66.4 & 91.4 & 43.9 & 53.3 & 69.6 & 55.1 & 15.1 \\
\hline $\mathrm{LNAA}^{2}, \mu \mathrm{M}$ & 933.5 & 893.8 & 1148.0 & 909.8 & 891.0 & 933.0 & 875.7 & 100.38 \\
\hline Trp: LNAA ${ }^{3}$ & 0.085 & 0.083 & 0.119 & $0.174 *$ & $0.139^{*}$ & $0.164 *$ & $0.173^{*}$ & 0.015 \\
\hline \multicolumn{9}{|c|}{ Beagles } \\
\hline \multicolumn{9}{|c|}{ Dietary Trp, $\%$} \\
\hline & 0.092 & 0.126 & 0.148 & 0.182 & 0.216 & 0.249 & 0.283 & \\
\hline & $n=4$ & $n=4$ & $n=4$ & $n=4$ & $n=4$ & $n=4$ & $n=4$ & SEM \\
\hline $\operatorname{Trp}, \mu \mathrm{M}$ & 88.9 & 112.1 & 105.6 & 133.4 & 154.5 & 162.6 & 159.1 & 20.2 \\
\hline Ala, $\mu \mathrm{M}$ & 585.1 & 649.8 & 577.8 & 514.8 & 628.8 & 587.6 & 594.9 & 51.6 \\
\hline Val, $\mu \mathrm{M}$ & 292.2 & 305.7 & 295.3 & 318.5 & 273.1 & 301.7 & 251.0 & 25.2 \\
\hline Phe, $\mu \mathrm{M}$ & 91.5 & 100.6 & 101.5 & 82.6 & 69.1 & 91.9 & 79.1 & 9.7 \\
\hline Ile, $\mu \mathrm{M}$ & 216.3 & 150.1 & 151.5 & 131.8 & 105.5 & 138.4 & 119.3 & 16.6 \\
\hline Leu, $\mu \mathrm{M}$ & 172.0 & 182.2 & 173.1 & 142.0 & 136.8 & 150.7 & 142.8 & 18.3 \\
\hline Lys, $\mu \mathrm{M}$ & 262.4 & 308.1 & 289.8 & 274.0 & 263.6 & 292.0 & 266.2 & 30.6 \\
\hline Tyr $\mu \mathrm{M}$ & 78.7 & 93.9 & 93.6 & 87.2 & 82.6 & 81.4 & 79.6 & 7.9 \\
\hline LNAA, $\mu \mathrm{M}$ & 1022.9 & 1139.0 & 1103.3 & 1036.0 & 930.7 & 1056.2 & 938.46 & 90.4 \\
\hline Trp: LNAA & 0.091 & 0.118 & 0.095 & 0.142 & 0.166 & 0.153 & 0.176 & 0.028 \\
\hline \multicolumn{9}{|c|}{ Labrador Retrievers } \\
\hline \multicolumn{9}{|c|}{ Dietary Trp, $\%$} \\
\hline & 0.092 & 0.126 & 0.148 & 0.182 & 0.216 & 0.249 & 0.283 & \\
\hline & $n=5$ & $n=5$ & $n=5$ & $n=5$ & $n=5$ & $n=5$ & $n=5$ & SEM \\
\hline $\operatorname{Trp}, \mu \mathrm{M}$ & 51.3 & 99.0 & 109.5 & $135.1^{*}$ & $118.9^{*}$ & $158.5^{*}$ & $140.3^{*}$ & 17.9 \\
\hline Ala, $\mu \mathrm{M}$ & 655.2 & 750.7 & 693.6 & 745.3 & 646.5 & 676.1 & 702.2 & 57.2 \\
\hline Val, $\mu \mathrm{M}$ & 265.9 & 288.7 & 251.1 & 309.7 & 246 & 293.6 & 253.7 & 23.5 \\
\hline Phe, $\mu \mathrm{M}$ & 79.0 & 92.2 & 73.8 & 85.9 & 80.8 & 86.4 & 93.5 & 7.9 \\
\hline $\mathrm{Ile}, \mu \mathrm{M}$ & 119.8 & 133.0 & 106.8 & 132.4 & 121.0 & 120.1 & 127.1 & 11.9 \\
\hline Leu, $\mu \mathrm{M}$ & 158.7 & 153.5 & 126.0 & 139.4 & 137.0 & 136.6 & 150.3 & 14.6 \\
\hline Lys, $\mu \mathrm{M}$ & 267.3 & 253.8 & 234.8 & 270.4 & 260.3 & 250.2 & 281.3 & 18.7 \\
\hline Tyr $\mu \mathrm{M}$ & 85.6 & 101.6 & 95.4 & 96.6 & 96.5 & 83.8 & 89.0 & 9.3 \\
\hline LNAA, $\mu \mathrm{M}$ & 976.5 & 1025.0 & 887.9 & 1034.3 & 942.6 & 969.4 & 991.9 & 69.8 \\
\hline Trp: LNAA & 0.055 & 0.096 & 0.123 & $0.140 *$ & $0.132 *$ & $0.173^{*}$ & $0.143^{*}$ & 0.024 \\
\hline
\end{tabular}

${ }^{1}$ Standard error of the mean, $n=4$ at each concentration of dietary Trp for Miniature Dachshunds and Beagles, $n=5$ for Labrador Retrievers. ${ }^{2}$ Large neutral amino acids: Val, Phe, Ile, Leu, Lys, Tyr.

${ }^{3}$ Ratio of Trp to LNAA.

*Significantly different at $P \leq 0.05$ when compared with the lowest concentration of dietary $\operatorname{Trp}(\operatorname{Trp}=0.092 \%$ on dry-matter basis) using the Dunnett test.

to the inclusion of supplemental DL-Methionine and/or L-Lysine in commercial dog diets.

In growing dogs, the current recommended Trp requirement (NRC, 2006) was extrapolated from empirical data using immature English Pointers (Czarnecki and Baker, 1982). In that study, Czarnecki and Baker reported minimal Trp requirements for growing dogs of 6 to 10 and 12 
Table 5. Recommended dietary Trp inclusions for adult dogs at maintenance by AAFCO, FEDIAF, NRC, and the present study

\begin{tabular}{|c|c|c|c|c|c|c|c|c|c|c|}
\hline & \multirow[b]{2}{*}{$\mathrm{AAFCO}^{1}$} & \multirow[b]{2}{*}{ FEDIAF $^{2}$} & \multicolumn{2}{|c|}{$\mathrm{NRC}^{3}$} & \multicolumn{2}{|c|}{ Miniature Dachshunds } & \multicolumn{2}{|c|}{ Beagles } & \multicolumn{2}{|c|}{ Labrador Retrievers } \\
\hline & & & $\mathrm{MR}^{4}$ & RA & MR & CI & MR & $\mathrm{CI}$ & MR & $\mathrm{CI}$ \\
\hline$\overline{\mathrm{g} / 100 \mathrm{~g} \mathrm{DM}^{5}}$ & 0.16 & 0.21 & 0.11 & 0.14 & 0.154 & 0.187 & 0.218 & 0.269 & 0.157 & 0.204 \\
\hline g/Mcal ME & $0.40^{6}$ & 0.53 & 0.28 & 0.35 & 0.370 & 0.451 & 0.524 & 0.649 & 0.378 & 0.489 \\
\hline $\mathrm{mg} / \mathrm{kg} \mathrm{BW}$ & & & & & 20.58 & $\begin{array}{c}25.01 \\
(30.42)^{7}\end{array}$ & 38.78 & $\begin{array}{c}47.92 \\
(26.40)\end{array}$ & 20.94 & $\begin{array}{c}27.21 \\
(19.52)\end{array}$ \\
\hline
\end{tabular}

\footnotetext{
${ }^{1}$ Association of American Feed Control Officials Manual (2014).

${ }^{2}$ European Pet Food Industry Federation Nutritional guidelines for complete and complementary pet food for cats and dogs (2013).

${ }^{3}$ Nutrient requirements of dog and cats. National Research Council (2006).

${ }^{4} \mathrm{CI}=$ Confidence interval; $\mathrm{MR}=$ Minimal requirement; $\mathrm{RA}=$ recommended allowance

${ }^{5}$ Values for $\mathrm{g} / 100 \mathrm{~g}$ DM are determined assuming a dietary energy density of 4,000 kcal ME/kg.

${ }^{6}$ Assuming dietary energy density of $4,000 \mathrm{kcal} \mathrm{ME} / \mathrm{kg}$.

${ }^{7}$ Values in parentheses represent NRC recommendation for Trp requirement for adult dogs at maintenance converted from $\mathrm{mg} / \mathrm{kg} \mathrm{BW} \mathrm{BW}^{0.75}$ to $\mathrm{mg} /$ kg BW using the average BW of individual breeds.
}

to 14 wk of age to be $0.16 \%$ and $0.12 \%$, respectively. Similarly, Burns and Milner (1982) determined the Trp MR of immature Beagles to be $0.15 \%$. These requirements were determined using nitrogen balance and growth performance techniques in growing animals where only 10 to $15 \%$ of the total AA requirement is represented by the AA needed for maintenance (Moughan, 1995); such techniques lose sensitivity when carried out with adult animals at maintenance. In mature animals, changes in nitrogen balance, BW, and whole-body protein pool are marginal and can accommodate different concentrations of the test AA without affecting protein-related measurements, but potentially decreasing secondary pathways (i.e., Trp as a kynurenine pathway precursor; Badawy, 2017). Thus, these studies should not be relied upon as the sole source of data to generate AA requirements in adult dogs and further studies are required to examine the effects of dietary Trp on secondary measures. The IAAO technique represents a more sensitive method of evaluating changes in protein synthesis, allowing for the establishment of whole body AA requirements in adult dogs (Shoveller et al., 2017). Amino acid oxidation techniques generally result in AA recommendations much higher than those suggested based on nitrogen retention (Zello et al., 1995; Elango et al., 2012). LazarisBruuner et al. (1998) determined dietary Trp requirements for adult women using IAAO techniques and reported a requirement $43 \%$ higher than that previously established via traditional nitrogen balance techniques (Leverton et al., 1956). Ultimately, more data from dose-response studies are needed for the determination and confirmation of Trp (and other indispensable AA) requirements for dogs of varying breed sizes and life-stages.
We have only presented serum AA concentrations for Trp and Ala, since those AA changed among dietary treatments, as well as for LNAA due to the interfering role they play in Trp secondary metabolism (serotonergic pathway) via competitive inhibition of shared AA transporters (Fernstrom, 2013). Only the linear phase in the 2-phase model was significant indicating that Trp concentrations increased with higher Trp supplementation and Trp requirements are much lower than $0.092 \%$. Theoretically, concentration of an indispensable AA should not increase at different concentrations of intake below the requirements and increase thereafter at higher concentrations. However, considering the alternative IAAO methods presented in the current study, this data set should not be utilized to determine Trp requirements. Ala concentrations were not modified with increased Ala supplementation for any breed. The lack of difference in serum Ala can be attributed to hepatic utilization of absorbed Ala into glucose before reaching systemic circulations (Rémésy and Demigne, 1983; Mansilla et al., 2018b). Concentrations of LNAA did not differ among dietary treatments for any breed, but this was expected as the LNAA were not different among dietary treatments. However, for Labradors and Dachsunds, dogs fed diets with the 4 highest concentrations of Trp had significantly higher serum Trp: LNAA ratios compared with dogs fed at the lowest Trp concentration. This demonstrates that with sufficient supplementation of Trp and without additional dietary LNAA, the Trp: LNAA ratio can be increased in serum, increasing the likelihood of Trp crossing the blood-brain-barrier and contributing to serotonin synthesis (Fernstrom, 2013). Considering the differences expected from the use of crystalline AA as 
well as laboratory-to-laboratory variation in analyses, all serum AA concentrations were within reference range for healthy, adult dogs at maintenance (Delaney et al., 2003; NRC, 2006).

The similarity in calorimetry responses $(\mathbf{E E}$, resting and fed; $\mathbf{R Q}$, fated and fed) among the concentrations of $\operatorname{Trp}$ fed suggests that differing the concentrations of dietary Trp did not affect energy or macronutrient metabolism. This was akin to what was observed in the other study presented in this series, helping us to validate the data accrued from previous reports using the same animals (Mansilla et al., 2018a). The fasting RQ values indicate energy production via fat oxidation, and the increase in RQ when fed suggests a preferential shift to protein and carbohydrate catabolism (DuBois, 1924) as expected. Resting EE was lowest for the Miniature Dachshunds, which was also in agreement with our previous report (Mansilla et al., 2018a). This implies that small breed dogs have different nutrient utilization than medium or large breeds, at least while in a fasted state. Fasting RQ, fed RQ, fed $\mathrm{VO}_{2}$, and fed $\mathrm{VCO}_{2}$ values are in agreement with our previous report (Mansilla et al., 2018a).

The present study is part of a series of experiments where the requirements for Phe have been previously estimated for adult dogs of different breeds using the direct AA oxidation (DAAO) technique (Mansilla et al., 2018a). For Phe, the DAAO results indicated that the dietary requirements were similar across different breeds, and that the estimated requirements were in agreement with those presented by the NRC (NRC, 2006; Mansilla et al., 2018a). The establishment of indispensable AA requirements of adult dogs using AA oxidation techniques would bridge a knowledge gap and assist in the maintenance of an animal's health through dietary optimization. With the dearth of information regarding adult dog AA requirements, there is little guidance to the pet food industry as to how to more precisely deliver amino acids with consideration of other dietary nutrients and this lack of knowledge may hamper consideration of novel protein ingredients. A deeper understanding of AA metabolism in dogs and all the variables that may affect it is required to support the long-term sustainability of the pet food industry. However, although this series of reports has demonstrated the value of AA oxidation techniques, the authors do recognize that long-term feeding studies would be necessary to confirm these findings and justify modifications of AA requirements by regulatory bodies. As well, the authors acknowledge that only spayed and neutered dogs were used for this trial; therefore, no conclusions can be drawn regarding how or if Trp requirements would differ for intact dogs. Further research is warranted to investigate whether hormonal status alters amino acid requirements of adult dogs.

\section{CONCLUSIONS AND IMPLICATIONS}

The data presented suggest that the dietary Trp requirements are higher for Beagles compared with Labradors or Dachshunds, and that the NRC recommendations are underestimated for adult dogs at maintenance. The estimates derived from this experiment are based on a diet supplemented with crystalline Trp; thus, if formulating commercial adult dog diets to meet the Trp requirements suggested in this report, attention must be paid to the reduced nutrient availability of intact proteinbased ingredients. The estimated Trp requirements derived from the semipurified diets used in this report likely underestimate Trp needs in adult dogs fed commercial maintenance diets formulated with natural protein sources. Additionally, considering the low concentrations that $\operatorname{Trp}$ is found in most protein-based ingredients, supplementation of synthetic Trp may be essential in order to formulate adult dog diets to meet the requirements suggested herein. Further research determining indispensable AA requirements for dogs of varying life-stages and breeds is warranted.

Authors' contributions: A.K.S. designed research. A.K.S. and L.F. conducted research, and all authors analyzed the data and wrote the manuscript. A.K.S. had primary responsibility for the final content. All authors read and approved the final manuscript.

Conflict of interest statement. The work was funded by the Procter \& Gamble Co. A.K.S. and L.F. were employees of the Procter \& Gamble Co. and Mars Pet Care; L.F. is now employed by Mars Pet Care, and A.K.S. is now faculty at the University of Guelph. J.R.T and W.D.M. have no conflicts of interest.

\section{LITERATURE CITED}

Association of American Feed Control Officials. 2014. AAFCO Manual. AAFCO Inc., West Lafayette, IN.

Badawy, A. A. 2017. Kynurenine pathway of tryptophan metabolism: regulation and functional aspects. Int. J. Tryptophan Res. 10:1-20. doi:10.1177/1178646917 691938

Ball, R. O., and H. S. Bayley. 1984. Tryptophan requirement of the $2.5-\mathrm{kg}$ piglet determined by the oxidation of an 
indicator amino acid. J. Nutr. 114:1741-1746. doi:10.1093/ jn/114.10.1741

Bross, R., R. O. Ball, J. T. Clarke, and P. B. Pencharz. 2000. Tyrosine requirements in children with classical PKU determined by indicator amino acid oxidation. Am. J. Physiol. Endocrinol. Metab. 278:E195-E201. doi:10.1152/ajpendo.2000.278.2.E195

Burns, R. A., and J. A. Milner. 1982. Threonine, tryptophan and histidine requirements of immature beagle dogs. J. Nutr. 112:447-452. doi:10.1093/jn/112.3.447

Coleman, R. A., R. F. Bertolo, S. Moehn, M. A. Leslie, R. O. Ball, and D. R. Korver. 2003. Lysine requirements of pre-lay broiler breeder pullets: determination by indicator amino acid oxidation. J. Nutr. 133:2826-2829. doi:10.1093/jn/133.9.2826

Courtney-Martin, G., R. Bross, M. Raffi, J. T. Clarke, R. O. Ball, and P. B. Pencharz. 2002. Phenylalanine requirement in children with classical PKU determined by indicator amino acid oxidation. Am. J. Physiol. Endocrinol. Metab. 283:E1249-E1256. doi:10.1152/ajpendo.0319.2001

Czarnecki, G. L., and D. H. Baker. 1982. Utilization of D- and L-tryptophan by the growing dog. J. Anim. Sci. 55:14051410. doi:10.2527/jas1982.5561405x

Delaney, S. J., P. H. Kass, Q. R. Rogers, and A. J. Fascetti. 2003. Plasma and whole blood taurine in normal dogs of varying size fed commercially prepared food. J. Anim. Physiol. Anim. Nutr. (Berl). 87:236-244. doi:10.1046/j.1439-0396.2003.00433.x

Di Buono, M., L. J. Wykes, R. O. Ball, and P. B. Pencharz. 2001. Total sulfur amino acid requirement in young men as determined by indicator amino acid oxidation with L-[1-13C]phenylalanine. Am. J. Clin. Nutr. 74:756-760. doi:10.1093/ajcn/74.6.756

DuBois, E. G. 1924. A graphic representation of the respiratory quotient and the percentage of calories from protein, fat and carbohydrate. J. Biol. Chem. 59:43-49.

Elango, R., R. O. Ball, and P. B. Pencharz. 2012. Recent advances in determining protein and amino acid requirements in humans. Br. J. Nutr. 108(Suppl 2):S22-S30. doi:10.1017/S0007114512002504

Elango, R., M. A. Humayun, R. O. Ball, and P. B. Pencharz. 2007. Lysine requirement of healthy school-age children determined by the indicator amino acid oxidation method. Am. J. Clin. Nutr. 86:360-365. doi:10.1093/ajen/86.2.360

European Pet Food Industry Federation. 2013. Nutritional guidelines for complete and complementary pet food for cats and dogs. Bruxelles, Belgium: FEDIAF.

Fernstrom, J. D. 2013. Large neutral amino acids: dietary effects on brain neurochemistry and function. Amino Acids 45:419-430. doi:10.1007/s00726-012-1330-y

Hsu, J. W., L. A. Goonewardene, M. Rafii, R. O. Ball, and P. B. Pencharz. 2006. Aromatic amino acid requirements in healthy men measured by indicator amino acid oxidation. Am. J. Clin. Nutr. 83:82-88. doi:10.1093/ajcn/83.1.82

Kriengsinyos, W., L. J. Wykes, R. O. Ball, and P. B. Pencharz. 2002. Oral and intravenous tracer protocols of the indicator amino acid oxidation method provide the same estimate of the lysine requirement in healthy men. J. Nutr. 132:2251-2257. doi:10.1093/jn/132.8.2251

Lazaris-Brunner, G., M. Rafii, R. O. Ball, and P. B. Pencharz. 1998. Tryptophan requirement in young adult women as determined by indicator amino acid oxidation with L-[13C]phenylalanine. Am. J. Clin. Nutr. 68:303-310. doi:10.1093/ajen/68.2.303
Leverton, R. M., N. Johnson, J. Pazur, and J. Ellison. 1956. The quantitative amino acid requirements of young women. III. Tryptophan. J. Nutr. 58:219-229. doi:10.1093/ jn/58.2.219

Mager, D. R., L. J. Wykes, R. O. Ball, and P. B. Pencharz. 2003. Branched-chain amino acid requirements in schoolaged children determined by indicator amino acid oxidation (IAAO). J. Nutr. 133:3540-3545. doi:10.1093/ jn/133.11.3540

Mansilla, W. D., A. Gorman, L. Fortener, and A. K. Shoveller. 2018a. Dietary phenylalanine requirements are similar in small, medium, and large breed adult dogs using the direct amino acid oxidation technique. J. Anim. Sci. 96:31123120. doi:10.1093/jas/sky208

Mansilla, W. D., K. E. Silva, C. Zhu, C. M. Nyachoti, J. K. Htoo, J. P. Cant, and C. F. M. de Lange. 2018b. Ammonianitrogen added to low-crude-protein diets deficient in dispensable amino acid-nitrogen increases the net release of alanine, citrulline, and glutamate post-splanchnic organ metabolism in growing pigs. J. Nutr. 148:1081-1087. doi:10.1093/jn/nxy076

Milner, J. A. 1979. Assessment of the essentiality of methionine, threonine, tryptophan, histidine and isoleucine in immature dogs. J. Nutr. 109:1351-1357. doi:10.1093/ jn/109.8.1351

Moehn, S., R. F. Bertolo, P. B. Pencharz, and R. O. Ball. 2004. Indicator amino acid oxidation responds rapidly to changes in lysine or protein intake in growing and adult pigs. J. Nutr. 134:836-841. doi:10.1093/jn/134.4.836

Moehn, S., A. K. Shoveller, M. Rademacher, and R. O. Ball. 2008. An estimate of the methionine requirement and its variability in growing pigs using the indicator amino acid oxidation technique. J. Anim. Sci. 86:364-369. doi:10.2527/jas.2006-601

Moughan, P. J. 1995. Modelling protein metabolism in the pig - critical evaluation of a simple reference model. In: Modelling growth in the pig. P. J. Moughan, M. W. A. Verstegen, and M. I. Visser-Reyneveld. editors, Wageningen press, The Netherlands. p. 103-112.

National Research Council. 2006. Nutrient requirements of dogs and cats. 2nd rev. ed. Natl. Acad. Press, Washington, DC.

Official Methods of Analysis of AOAC International. 2000. AOAC Int., Gaithersburg, MD.

Pencharz, P. B., and R. O. Ball. 2003. Different approaches to define individual amino acid requirements. Annu. Rev. Nutr. 23:101-116. doi:10.1146/annurev.nutr.23.011702.073247

Rafii, M., J. M. McKenzie, S. A. Roberts, G. Steiner, R. O. Ball, and P. B. Pencharz. 2008. In vivo regulation of phenylalanine hydroxylation to tyrosine, studied using enrichment in apob-100. Am. J. Physiol. Endocrinol. Metab. 294:E475-E479. doi:10.1152/ajpendo.00604.2007

Rémésy, C., and C. Demigné. 1983. Changes in availability of glucogenic and ketogenic substrates and liver metabolism in fed or starved rats. Ann. Nutr. Metab. 27:57-70. doi: $10.1159 / 000176624$

Richard, D. M., M. A. Dawes, C. W. Mathias, A. Acheson, N. HillKapturczak, and D. M. Dougherty. 2009. L-tryptophan: basic metabolic functions, behavioral research and therapeutic indications. Int. J. Tryptophan Res. 2:45-60.

Roberts, S. A., J. M. Thorpe, R. O. Ball, and P. B. Pencharz. 2001. Tyrosine requirement of healthy men receiving a fixed phenylalanine intake determined by using indicator amino acid oxidation. Am. J. Clin. Nutr. 73:276-282. doi:10.1093/ajen/73.2.276 
Sanderson, S. L., K. L. Gross, P. N. Ogburn, C. Calvert, G. Jacobs, S. R. Lowry, K. A. Bird, L. A. Koehler, and L. L. Swanson. 2001. Effects of dietary fat and L-carnitine on plasma and whole blood taurine concentrations and cardiac function in healthy dogs fed protein-restricted diets. Am. J. Vet. Res. 62:1616-1623. doi:10.2460/ajvr.2001.62.1616

Shoveller, A. K., J. J. Danelon, J. L. Atkinson, G. M. Davenport, R. O. Ball, and P. B. Pencharz. 2017. Calibration and validation of a carbon oxidation system and determination of the bicarbonate retention factor and the dietary phenylalanine requirement, in the presence of excess tyrosine, of adult, female, mixed-breed dogs,. J. Anim. Sci. 95:2917-2927. doi:10.2527/jas.2017.1535

Tabiri, H. Y., R. F. Bertolo, R. O. Ball, and D. R. Korver. 2002. Development of the indicator amino acid oxidation technique in chickens: calibration of oxidation system and determination of bicarbonate retention factor. Poult. Sci. 81:1020-1025. doi:10.1093/ps/81.7.1020

Tang, M., G. P. McCabe, R. Elango, P. B. Pencharz, R. O. Ball, and W. W. Campbell. 2014. Assessment of protein requirement in octogenarian women with use of the indicator amino acid oxidation technique. Am. J. Clin. Nutr. 99:891-898. doi:10.3945/ajcn.112.042325
Triebwasser, K. C., P. B. Swan, L. M. Henderson, and J. A. Budny. 1976. Metabolism of D- and L-tryptophan in dogs. J. Nutr. 106:642-652. doi:10.1093/jn/106.5.642

Turner, J. M., M. A. Humayun, R. Elango, M. Rafii, V. Langos, R. O. Ball, and P. B. Pencharz. 2006. Total sulfur amino acid requirement of healthy school-age children as determined by indicator amino acid oxidation technique. Am. J. Clin. Nutr. 83:619-623. doi:10.1093/ajcn.83.3.619

Ward, J. 1976. The amino acid requirements of the adult dog. Ph.D. dissertation, Wolfson College, University of Cambridge, UK.

Weir, J. B. 1949. New methods for calculating metabolic rate with special reference to protein metabolism. J. Physiol. 109:1-9.

Wilson, D. C., M. Rafii, R. O. Ball, and P. B. Pencharz. 2000. Threonine requirement of young men determined by indicator amino acid oxidation with use of L-[1-(13)C]phenylalanine. Am. J. Clin. Nutr. 71:757-764. doi:10.1093/ ajen/71.3.757

Zello, G. A., L. J. Wykes, R. O. Ball, and P. B. Pencharz. 1995. Recent advances in methods of assessing dietary amino acid requirements for adult humans. J. Nutr. 125:29072915. doi:10.1093/jn/125.12.2907 